\title{
Observations of Doppler and delay spreads on HF signals received over polar cap and trough paths at various stages of the solar cycle
}

\author{
A. J. Stocker, ${ }^{1}$ E. M. Warrington, ${ }^{1}$ and D. R. Siddle ${ }^{1}$ \\ Received 9 July 2013; revised 23 September 2013; accepted 4 October 2013; published 24 October 2013.
}

[1] Information on delay and Doppler spreading is of importance to designers and operators of digital communication systems within the HF band since modem performance rapidly deteriorates when delay and Doppler spreads exceed system dependent thresholds. The northerly ionosphere is a particularly challenging region in this regard as delay and Doppler spreads often significantly exceed those for similar length paths at midlatitudes. This paper presents results from an extensive set of measurements undertaken over three northerly paths: two subauroral paths aligned along the midlatitude trough (Uppsala to Bruntingthorpe and Nurmijärvi to Bruntingthorpe) and one path (Qaanaaq to Ny-Âlesund) contained entirely within the polar cap. Measurements span the period from the 2009 solar minimum to July 2012, close to solar maximum and 2001, close to the previous solar maximum.

Citation: Stocker, A. J., E. M. Warrington, and D. R. Siddle (2013), Observations of Doppler and delay spreads on HF signals received over polar cap and trough paths at various stages of the solar cycle, Radio Sci., 48, 638-645, doi:10.1002/2013RS005264.

\section{Introduction}

[2] The northerly ionosphere is a region particularly associated with comparatively large values of delay and Doppler spreads imposed on HF signals reflected in these regions. Information on delay and Doppler spreading is of importance to designers and operators of digital communication systems within the HF band. When delay and Doppler spreads exceed system dependent thresholds, the modem performance rapidly deteriorates [Arthur and Maundrell, 1997]. Information on these parameters for various path geometries is therefore important for planning and operational reasons. The International Telecommunication Union, for instance, has identified the need for improvements to its propagation prediction models to include delay and Doppler spread parameters, in particular to support broadcasters in their use of the Digital Radio Mondiale (DRM) standard. The variation of the spread parameters for paths contained within two regions of the ionosphere is considered in this paper: the midlatitude or subauroral trough and the polar cap.

[3] The midlatitude trough is a region of the ionosphere of a few degrees in latitudinal extent where the electron density (and hence the critical frequency and the maximum usable frequency) is reduced [Tulunay and Sayers, 1971; Rodger

\footnotetext{
${ }^{1}$ Department of Engineering, University of Leicester, Leicester, UK.

Corresponding author: E. M. Warrington, Department of Engineering, University of Leicester, Leicester, LE1 7RH, UK. (emw@leicester.ac.uk)

C 2013 The Authors. Radio Science published by Wiley on behalf of the American Geophysical Union.

This is an open access article under the terms of the Creative Commons Attribution-NonCommercial-NoDerivs License, which permits use and distribution in any medium, provided the original work is properly cited, the use is non-commercial and no modifications or adaptations are made. 0048-6604/13/10.1002/2013RS005264
}

et al., 1992]. The trough generally occurs at night during the winter and equinoctial months, and rarely during the summer. The reduction in electron density means that the signal radiated by HF radio communication systems operating under the trough may no longer be ionospherically reflected along the great circle path. However, the signal can still be reflected from gradients in the poleward and equatorward walls of the trough or scattered from irregularities embedded in the trough or in the auroral region which lies just poleward of the trough [Zaalov et al., 2013]. If these signals then reach the receiver, they will arrive from directions away from the great circle and at times delayed with respect to normal propagation. Observations and simulations of these effects have been reported in a number of papers [Siddle et al., 2004a, 2004b; Stocker et al., 2007, 2009; Zaalov et al., 2005, 2007]. As well as directional and time-of-flight effects, the channel characteristics of such signals can be significantly different from normal on-great-circle propagation. For example, scattering from irregularities will tend to increase the Doppler spread of the signal, while if the signal arrives over several different paths (perhaps, some on and some off-great circle), this will increase the delay spread. The experimentally observed delay and Doppler spreads on a path affected by the trough at solar maximum were presented by Warrington and Stocker [2003], and at solar maximum and minimum by Stocker and Warrington [2011].

[4] Within the polar cap ionosphere, features of particular note are convecting patches and sun-aligned arcs of enhanced electron density that can lead to signals arriving in directions displaced from the great circle path by up to $100^{\circ}$ [Warrington et al., 1997; Zaalov et al., 2003]. Patches are formed in the dayside auroral oval [see, e.g., MacDougall and Jayachandran, 2007] during periods of southward directed Interplanetary Magnetic Field (IMF) $(\mathrm{Bz}<0)$ and the associated high levels of geomagnetic activity and generally convect in an antisunward direction across the polar cap into the nightside 


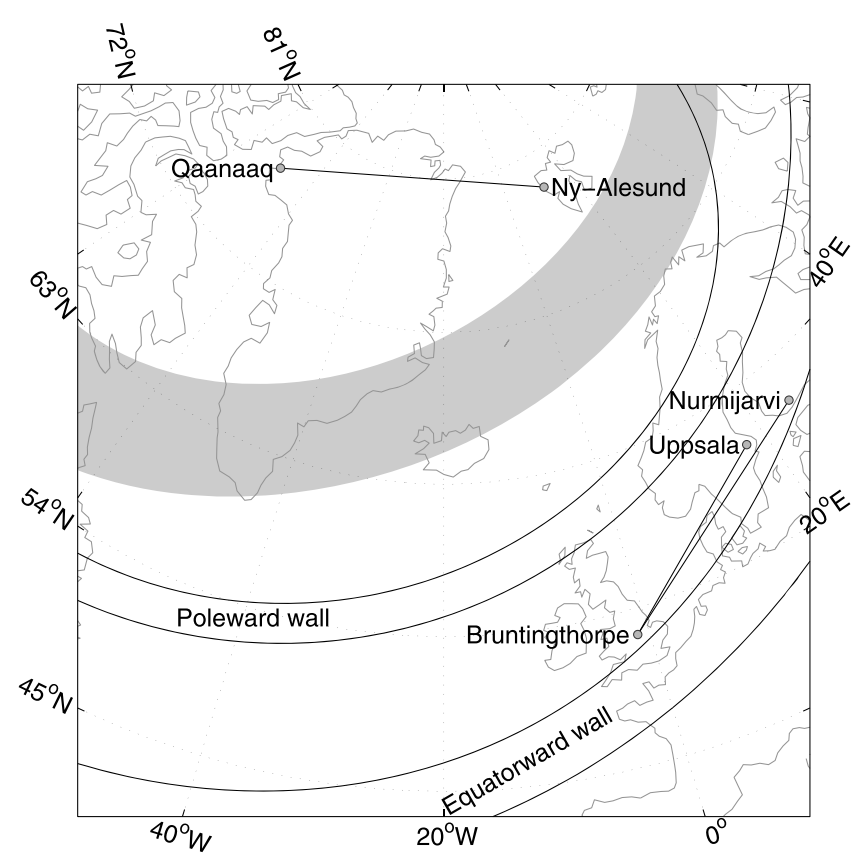

Figure 1. Map indicating the paths employed in the reported measurements. Typical positions of the auroral oval (shaded) and the midlatitude ionospheric trough are indicated for 1 April at 0200 UT with $K p=3$. Longitude and latitude are indicated in geographic coordinates.

auroral oval, whereas arcs occur when geomagnetic activity is low and the IMF is directed northward $(\mathrm{Bz}>0)$ and drift in a duskward direction [Buchau et al., 1983]. Reflections from these features can result in delay spreads well in excess of those expected for great circle propagation. Signals can arrive at the receiver over a range of directions with, for example, azimuthal standard deviations of up to $35^{\circ}$ at frequencies of $2.8,4.0$, and $4.7 \mathrm{MHz}$ being observed on one path from Isfjord, Svalbard to Alert [Warrington, 1998]. The ionosphere in this region is in constant motion, imposing a range of Doppler shifts and spreads onto the signals.

\section{Experimental Configuration}

[5] In this paper, we present experimental observations of delay and Doppler spreads over a polar cap path from Qaanaaq (Greenland) to Ny-Ålesund (Svalbard, $1705 \mathrm{~km}$ ), and two similar paths along the trough from Nurmijärvi (Finland) to Bruntingthorpe, near Leicester, (UK, $1800 \mathrm{~km})$ and Uppsala (Sweden) to Bruntingthorpe (UK, $1440 \mathrm{~km}$ ) (see Figure 1) at periods spanning the recent solar cycle (see Figure 2). For brevity, these paths are named in abbreviated form throughout the rest of the paper: Qaanaaq to NyÅlesund as QN, Nurmijärvi to Bruntingthorpe as NB, and Uppsala to Bruntingthorpe as UB. Doppler and delay spread measurements over the two trough paths have been the subject of previous publications (e.g., Warrington and Stocker, 2003; Stocker and Warrington, 2011); this paper extends the investigation to consider the effect of changing sunspot number on these parameters. Spread measurements over the polar cap path and investigation of their variation with sunspot number have not previously been published.

[6] The method used to make the measurements has been discussed in detail elsewhere [e.g., Siddle et al., 2004a; Stocker et al., 2009]. In brief, an approximately 100 W, 13-bit Barker encoded Binary Phase Shift Keying signal (1667 baud in 2001 and 2000 baud in 2006 onward) was radiated from the transmitter sites on a range of frequencies in the lower half of the HF band (4.6-18.4 MHz). For the trough paths, the signals were received on a circularly disposed antenna array at Bruntingthorpe, and for the polar cap path, a single channel receiver was employed. The parameters measured by the system include time-of-flight (TOF) and hence delay spread, Doppler frequency and hence Doppler spread, signal-to-noise ratio, and, although not discussed in this paper, directional characteristics (i.e., azimuth and elevation) at Bruntingthorpe only. There were some slight operational differences between the systems used at sunspot maximum and minimum, and these are summarized in Table 1.

[7] The multipath and Doppler spread parameters are defined here in a similar manner to that employed by Angling et al. [1998] and Stocker and Warrington [2011].

[8] 1. Composite multipath spread (CMPS): This is the time between the rising edge of the first detected mode and the falling edge of the last detected mode, with a correction applied for the width of the transmitted pulse. Weak modes, i.e., those with an integrated power (i.e. summed over all TOF where the mode exists) of more than $12 \mathrm{~dB}$ below the integrated power of the strongest mode were excluded from the processing.

[9] 2. Doppler spread: This is the narrowest spectral width containing $80 \%$ of the received signal power. In all cases, a correction is applied for the base noise level.

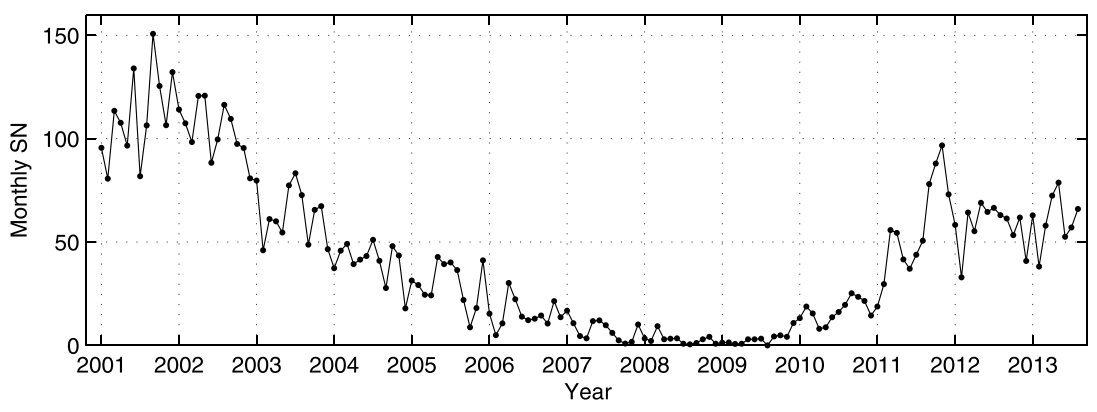

Figure 2. Variation in smoothed sunspot number over the period of study. The quantity plotted is the monthly mean international sunspot number downloaded from the Space Weather Prediction Center, US National Oceanic and Atmospheric Administration, http://www.ngdc.noaa.gov/stp/space-weather/solardata/solar-indices/sunspot-numbers/international/. 
Table 1. Experimental Parameters of the Three Sets of Measurements

\begin{tabular}{lccc}
\hline & Data Included & Sample Resolution (min) & Doppler Resolution (Hz) \\
\hline Uppsala to Bruntingthorpe (UB) & January 2001 to December 2001 & 3 & 0.625 \\
Nurmijärvi to Bruntingthorpe (NB) & March 2009 to July 2012 & 2 & 0.5 \\
Qaanaaq to Ny-Ålesund (QN) & March 2009 to July 2012 & 2 & 0.5 \\
\hline
\end{tabular}

[10] For consistency with previous results [Angling et al., 1998; Warrington and Stocker, 2003; Stocker and Warrington, 2011], only observations with a signal-to-noise ratio (SNR), measured in a $3 \mathrm{kHz}$ bandwidth, of at least $6 \mathrm{~dB}$ were included in the statistical analysis. Cases affected by interferers were removed manually. Winter is defined as November-January, spring as February-April, summer as May-July, and autumn as August-October. Day time is considered as the $6 \mathrm{~h}$ period centered on path midpoint local noon and nighttime as the $6 \mathrm{~h}$ period centered on local midnight. Measurements made at other times are not presented here.

\section{Observations}

\subsection{Example Measurements for the Qaanaaq to Ny-Ålesund Path}

[11] Example measurements of TOF, CMPS, Doppler shift, and Doppler spread for the $10.39 \mathrm{MHz}$ signal received (regardless of SNR) over the QN path for the period 26-31 October 2011 are presented in Figure 3. Several features are evident in these data.

[12] 1. Propagation via $1 F 2$ mode with a TOF of just over $6 \mathrm{~ms}$ or $1 \mathrm{E}$ mode (TOF just under $6 \mathrm{~ms}$ ) is present for much of the time. Variations are evident in the 1 hop TOF (e.g., at around 02:00 on 27 October 2011 and at around 00:00 UT on 30 October 2011), often associated with features in the other parameters. At times, $2 \mathrm{~F}$ propagation with a TOF of around $6.8 \mathrm{~ms}$ is also evident. As with the 1 hop traces, this is not constant, and variations are often reflected in other parameters.

[13] 2. As expected from observing the TOF traces, the CMPS is usually less than $0.5 \mathrm{~ms}$, increasing significantly at times when a 2 hop mode is evident to spread values of up to around $2 \mathrm{~ms}$.

[14] 3. The Doppler frequency trace shows significant scatter in places, in particular at the start of the reception period shown in the figure. Also evident in this parameter are marked swings in Doppler frequency from a high offset value to a low offset value, often associated with an increase in TOF (e.g., at 0200 UT, 27 October 2011). Such features are consistent with the passage over the propagation path of convecting polar patches - this is discussed in detail in Siddle et al. [2013].

[15] 4. Doppler spreads are typically less than $5 \mathrm{~Hz}$, but at times significantly exceed this value rising to upward of $20 \mathrm{~Hz}$.

[16] Statistical values of the Doppler and composite multipath spreads for this path and the NB trough path are now considered.

\subsection{Summary of Spread Parameters for the Nurmijärvi to Bruntingthorpe and Qaanaaq to $\mathbf{N y}$-Ålesund Paths}

[17] Presented in Table 2 are the 95th percentile values of Doppler and delay spreads for two of the paths considered in this paper (NB and QN) for the period 14 March 2009 to 1 July 2012 , a period spanning the current solar cycle minimum to around the recent peak (Figure 2).

[18] Doppler spreads observed on the trough path NB are small, all 95 th percentiles being $2.0 \mathrm{~Hz}$ or less. This contrasts
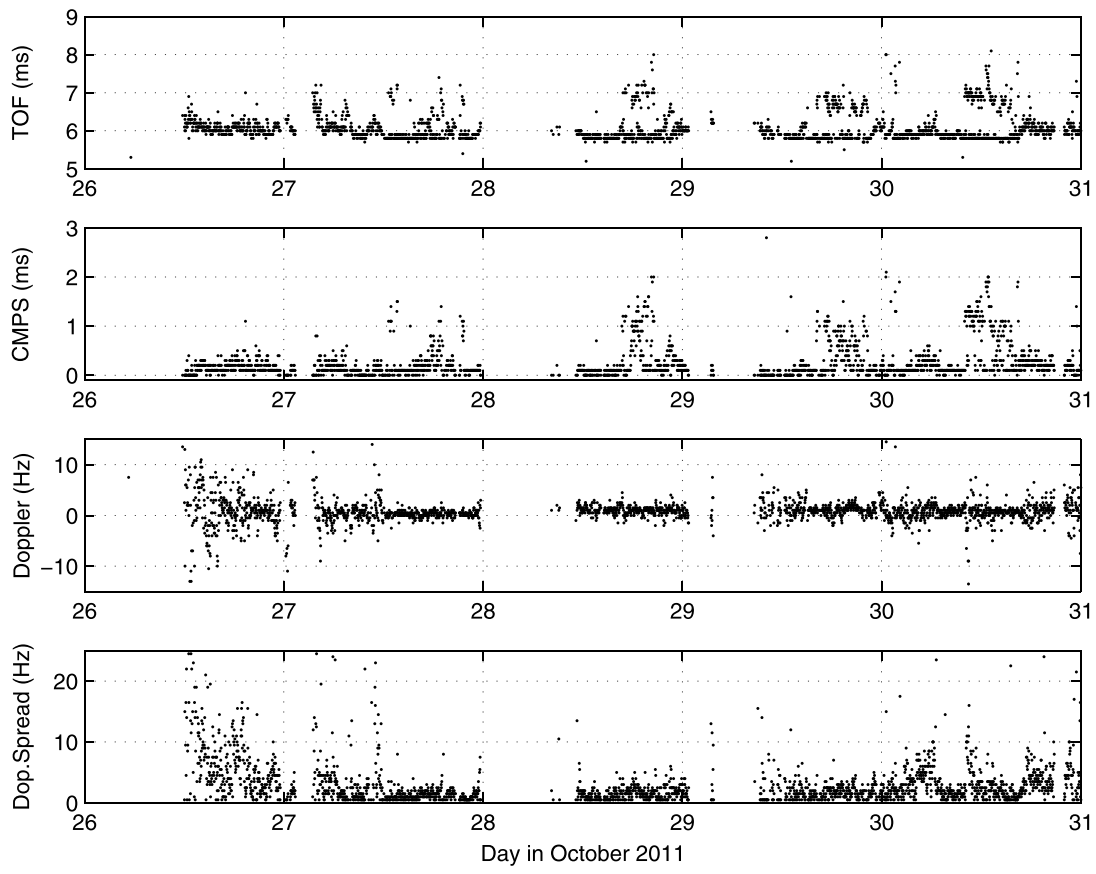

Figure 3. Measured times-of-flight (TOF), composite multipath spreads, Doppler shifts and Doppler spreads for the $10.39 \mathrm{MHz}$, Qaanaaq to Ny-Ålesund (QN) signal, 26-31 October 2011. 
Table 2. The 95th Percentiles of Doppler Spread and Delay Spread for the Period 14 March 2009 to 1 July 2012

\begin{tabular}{|c|c|c|c|c|c|c|c|c|}
\hline Frequency (MHz) & Path & 4.64 & 6.95 & 8.01 & 10.39 & 11.12 & 14.36 & 18.38 \\
\hline \multicolumn{9}{|l|}{ Doppler spread (Hz) } \\
\hline Equinox day & NB & 1.0 & 1.0 & 1.0 & 1.5 & 1.5 & 1.5 & 1.5 \\
\hline Summer day & & no data & 1.0 & 1.0 & 1.5 & 1.5 & 1.5 & 1.5 \\
\hline Winter day & & 1.5 & 1.5 & 1.5 & 1.5 & 1.5 & 1.5 & 1.5 \\
\hline Equinox night & & 1.5 & 1.5 & 1.5 & 1.5 & 1.5 & 1.5 & 1.5 \\
\hline Summer night & & 1.0 & 1.5 & 1.0 & 1.5 & 1.5 & 1.5 & 1.5 \\
\hline Winter night & & 1.5 & 1.5 & 1.5 & 1.5 & 2.0 & 2.0 & 0.5 \\
\hline Equinox day & QN & 1.0 & 5.0 & 5.0 & 4.5 & 4.0 & 7.0 & Not used \\
\hline Summer day & & no data & no data & 3.5 & 3.5 & 3.5 & 7.0 & \\
\hline Winter day & & 3.5 & 6.5 & 5.5 & 7.0 & 5.0 & 13.0 & \\
\hline Equinox night & & 2.0 & 5.5 & 6.0 & 5.5 & 4.0 & 10.5 & \\
\hline Summer night & & no data & 1.5 & 2.5 & 2.0 & 2.0 & 3.0 & \\
\hline Winter night & & 3.0 & 6.5 & 6.0 & 8.0 & 3.0 & 10.0 & \\
\hline \multicolumn{9}{|l|}{ Multipath (ms) } \\
\hline Equinox day & NB & 2.6 & 2.2 & 1.9 & 0.9 & 1.2 & 0.4 & 0.3 \\
\hline Summer day & & no data & 1.7 & 1.5 & 0.6 & 0.7 & 0.3 & 0.1 \\
\hline Winter day & & 4.1 & 1.7 & 2.0 & 0.7 & 1.5 & 0.7 & 0.6 \\
\hline Equinox night & & 2.5 & 1.0 & 0.8 & 0.3 & 0.3 & 0.2 & 0.1 \\
\hline Summer night & & 4.2 & 1.8 & 1.6 & 0.4 & 0.4 & 0.3 & 0.2 \\
\hline Winter night & & 1.3 & 0.3 & 0.2 & 0.2 & 0.2 & 0.2 & 0.1 \\
\hline Equinox day & QN & 0.7 & 0.9 & 0.5 & 0.3 & 0.2 & 0.3 & Not used \\
\hline Summer day & & no data & no data & 0.3 & 0.2 & 0.3 & 0.3 & \\
\hline Winter day & & 1.5 & 1.1 & 0.4 & 0.3 & 0.3 & 0.3 & \\
\hline Equinox night & & 0.2 & 0.6 & 0.4 & 0.3 & 0.2 & 0.3 & \\
\hline Summer night & & no data & 0.4 & 0.4 & 0.3 & 0.2 & 0.2 & \\
\hline Winter night & & 0.3 & 0.5 & 0.3 & 0.3 & 0.1 & 0.3 & \\
\hline
\end{tabular}

markedly with the polar cap path from QN where Doppler spread 95th percentile values range from 1.0 to $13.0 \mathrm{~Hz}$, but are with few exceptions greater than the values for the trough path. The largest values tend to occur in winter. Interestingly, in summer, the spreads tend to be higher during the day, this being particularly marked at $14.36 \mathrm{MHz}$. In this case, the large daytime value of spread at the 95th percentile arises from observations from a relatively small number of days, over half of the samples where the Doppler spread is greater than $7 \mathrm{~Hz}$ come from just 2 days (mostly 29 May 2012, but a few samples from 13 May 2011). Multipath spreads tend to be smaller for the QN polar cap path than for the NB trough path.

\subsection{Effects of Sunspot Number Variation}

[19] In a previous paper [Stocker and Warrington, 2011], the behavior of the Doppler and delay spreads at sunspot maximum and sunspot minimum was found for paths along the trough. Since observations were only available at extreme sunspot values (less than 20 at sunspot minimum and more than 100 at sunspot maximum), it was not possible to predict what the spreads would be at intermediate values. Having continued to make measurements through the recent sunspot maximum, it is now possible to determine the behavior of the spreads over a range of moderate sunspot values. In order to do this, the spreads have been collected into bins of 13 month smoothed sunspot number (SSN) of values $0-10,10-20$, etc. for different propagation paths, seasons, and day and night. In order to extend the range of sunspot values available, measurements of the spreads from the UB path collected in 2001 have been used as an indication of those that would have been measured on the similar, but slightly longer, NB path. While the observations presented by Stocker and Warrington [2011] indicate that this is a reasonable assumption for conditions of sunspot minimum, it is not certain that this will also be the case at sunspot maximum. However, propagation from similar ionospheric features (e.g., irregularities in the auroral oval) is likely to result in similar behavior in the spreads regardless of the path. The observations where the data are present in more than three bins appear to fall into five categories, the spread (1) is constant with SSN to the precision of the observations ( $\sim 0.5 \mathrm{~Hz}$ in Doppler, $0.1 \mathrm{~ms}$ in CMPS), (2) increases suddenly at a particular value of SSN, (3) changes linearly with SSN, (4) peaks at a particular value of SSN, and (5) a trend cannot be identified, e.g., because there are large, but unsystematic variations in the spread.

[20] Examples of the first four types of behavior of spreads at the 95th percentile are given in Figure 4, where the spread values have been plotted at the middle of each SSN bin (i.e., 5,15 , etc.). For the first type, where a sudden increase occurs, the range over which the change occurs (e.g., in the top left panel, the highest SSN at the low level is 65, while the lowest SSN at the high level is 105) and the mean low and high levels $(1.5 \mathrm{~Hz}$ and $4 \mathrm{~Hz}$ ) can be defined. For the second type, the gradient and intercept of the least squares fit can be calculated (these are shown on the figure). Where there is a peak (category 4), the distribution can be partially characterized by the position of the peak (e.g., $\mathrm{SSN}=35$ in the bottom left panel) and the value at the peak ( $5 \mathrm{~Hz}$ in this case). The case presented in the third row, left column, has been characterized as a constant value of spread because the sudden increase at high sunspot numbers is within the precision of the measurements.

[21] The behavior of the Doppler and composite multipath delay spreads is characterized for subauroral paths (i.e., NB and UB) in Tables 3 and 4, respectively, while that for polar cap path QN is given in Tables 5 and 6. In the tables, the " $\mathrm{L}$ " entries contain the constants to be used to construct a linear expression for the quantity. For example, in Table 4, the 

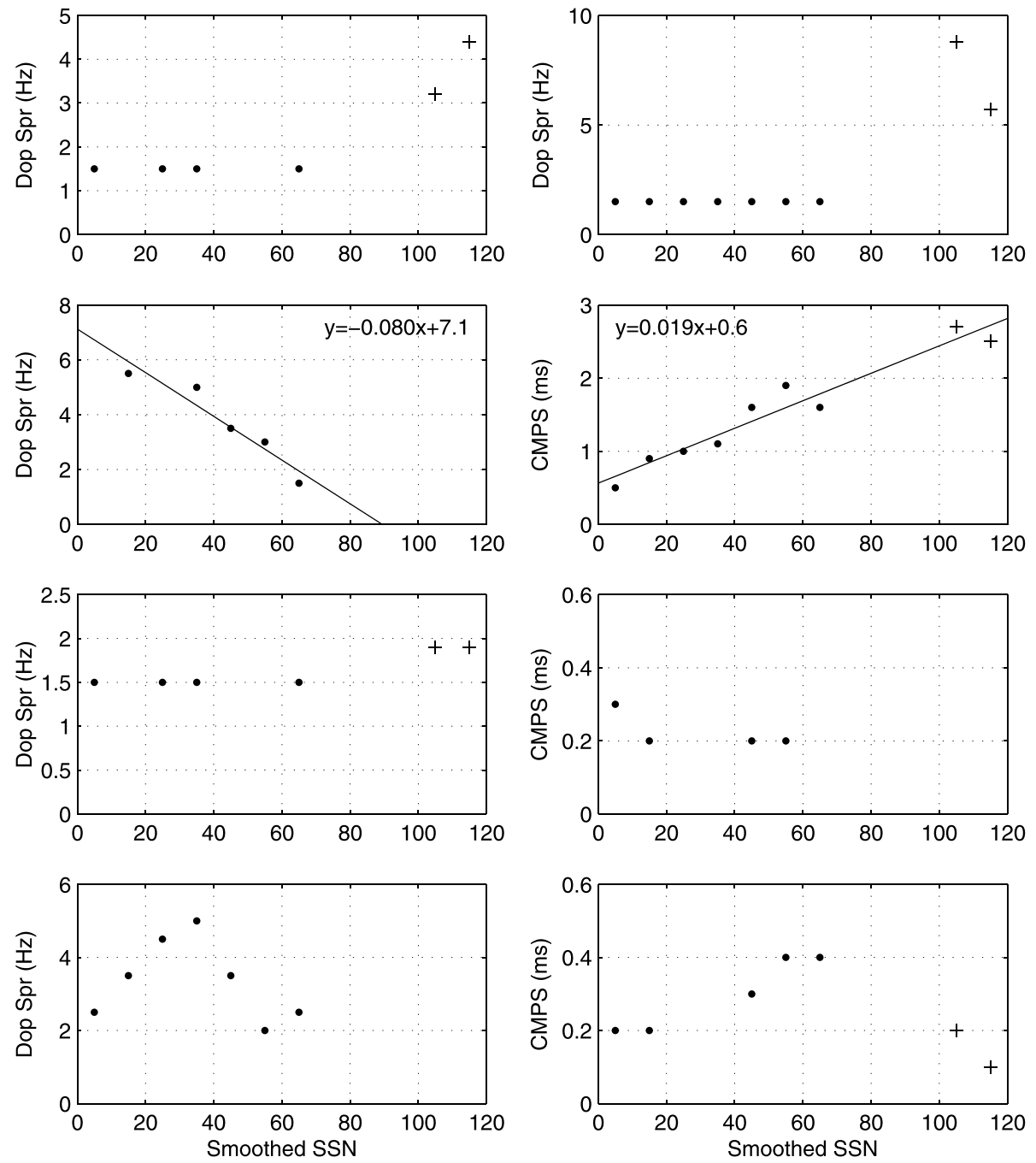

Figure 4. Examples of variation of spreads with smoothed sunspot number. (top row) A sudden increase in spread (left NB, 6.95 MHz, Winter night; right NB, $11.12 \mathrm{MHz}$, Equinox night) (second row) A linear change (left QN, 11.12 MHz, Equinox night; right NB, 11.12 MHz, Equinox day). (third row) Fixed value within the precision of the data (left NB, 6.95 MHz, Winter day; right QN, $11.12 \mathrm{MHz}$, Summer day). (bottom row) A peak in spread (left QN, 11.12 MHz, Equinox day; right NB, 14.36 MHz, Summer night). Note that points marked + are from UB and that only cases where there are more than 20 HF measurements are shown.

"L" numbers in the column under $11.12 \mathrm{MHz}$ in "Equinox Day", namely " $0.019+0.6$ " correspond to the algebraic expression in the corresponding panel in Figure 4 (row 2, column 2): $y=0.019 x+0.6$, in which $y$ is the composite multipath spread and $x$ is the SSN. The "P" entries show the SSN numbers at which a peak is located and the peak value. For example, in Table 4, the "P" numbers in the column under 14.36 $\mathrm{MHz}$ in "Summer Night", namely 55-65, 0.4 correspond to

Table 3. Behavior of 95th Percentile of Doppler Spread With Smoothed Sunspot Number for Nurmijärvi-Bruntingthorpe (Also Including Uppsala-Bruntingthorpe Data for 2001) ${ }^{\mathrm{a}}$

\begin{tabular}{|c|c|c|c|c|c|}
\hline Frequency $(\mathrm{MHz})$ & 4.64 & 6.95 & 8.01 & 11.12 & 14.36 \\
\hline \multicolumn{6}{|c|}{ Winter } \\
\hline Day & ND & Fix $=1.5$ & Fix $=1.5$ & SI:65-105, 1.5-2.5 & SI:65-105, 1.5-2.2 \\
\hline Night & Fix $=1.5$ & SI:65-105, 1.5-4 & ND & SI:65-105, 1.7-11.1 & SI:35-65, 1.3-7.4 \\
\hline \multicolumn{6}{|c|}{ Equinox } \\
\hline Day & ND & SI:65-105, 1.0-1.9 & Fix $=1.0$ & Fix $=1.5$ & Fix $=1.5$ \\
\hline Night & $\mathrm{L}: 0.009+0.9$ & SI:65-105, 1.5-2.9 & Fix $=1.0$ & SI: $65-105,1.5-7.3$ & SI:65-105, 1.4-6.4 \\
\hline \multicolumn{6}{|c|}{ Summer } \\
\hline Day & ND & ND & ND & Fix $=1.5$ & Fix $=1.5$ \\
\hline Night & $\mathrm{Fix}=1.0$ & $\mathrm{Fix}=1.5$ & Fix $=1.0$ & $\mathrm{Fix}=1.5$ & $\mathrm{Fix}=1.5$ \\
\hline
\end{tabular}

${ }^{\mathrm{a}} \mathrm{ND}$, insufficient data or otherwise unable to determine trend; Fix $=X \mathrm{~Hz}$. Spread is constant or varies only by measurement precision $(0.5 \mathrm{~Hz})-$ lower value is given; L, linear trend with gradient + constant given; SI, sudden increase between SSN values of $X-Y$ with mean spread levels (in Hz) before and after of A-B. 
Table 4. Behavior of 95th Percentile of Composite Multipath Spread With Smoothed Sunspot Number for Nurmijärvi-Bruntingthorpe (Also Including Uppsala-Bruntingthorpe Data for 2001) ${ }^{\mathrm{a}}$

\begin{tabular}{|c|c|c|c|c|c|}
\hline Frequency (MHz) & 4.64 & 6.95 & 8.01 & 11.12 & 14.36 \\
\hline \multicolumn{6}{|c|}{ Winter } \\
\hline Day & ND & ND & $\mathrm{L}: 0.025+1.0$ & L: $0.019+0.3$ & SI:35-65, 0.2-1.2 \\
\hline Night & $\mathrm{L}: 0.007+1.1$ & SI:65-105, 0.3-2.5 & ND & SI: $105-115,0.4-3.7$ & SI: $65-105,0.2-1.5$ \\
\hline \multicolumn{6}{|c|}{ Equinox } \\
\hline Day & ND & ND & $\mathrm{L}: 0.009+1.6$ & $L: 0.019+0.6$ & $L: 0.011+0.1$ \\
\hline Night & $\mathrm{L}: 0.007+2.4$ & $\mathrm{~L}: 0.014+0.6$ & $\mathrm{~L}: 0.018+0.2$ & $\mathrm{~L}: 0.005+0.2$ & $\mathrm{~L}: 0.002+0.1$ \\
\hline \multicolumn{6}{|c|}{ Summer } \\
\hline Day & ND & ND & ND & $L: 0.011+0.5$ & ND \\
\hline Night & $\mathrm{L}:-0.011+4.5$ & L: $0.013+1.5$ & $\mathrm{~L}: 0.022+0.8$ & L: $0.003+0.4$ & P:55-65, 0.4 \\
\hline
\end{tabular}

${ }^{\mathrm{a}} \mathrm{ND}$, insufficient data or otherwise unable to determine trend; L, linear trend defined by gradient + constant; SI, sudden increase between SSN values of $X-Y$ with mean spread levels (in ms) before and after of A-B; P, Peak located at a sunspot number of $X$ with a spread of $Y$ (in ms).

the peaked distribution in the panel in Figure 4 (row 4, column 2). Tabulated "SI" values are to be read similarly for representation of the SSN dependence of the dependent variable characterized by a sudden increase at particular SSN values. "Fix" denotes a constant within the precision of the observations for all SSN.

[22] Although observations are available at $10.39 \mathrm{MHz}$ and $18.38 \mathrm{MHz}$ for $\mathrm{NB}$, a change in transmission schedule part of the way through the period reported here means that there is insufficient range in sunspot values to draw sensible conclusions and these are omitted from Tables 3 and 4. Furthermore, only data from NB are available at $8.01 \mathrm{MHz}$ (since this frequency was not used for UL in 2001), so the $\mathrm{SSN}$ range is limited to $0-70$ at this frequency. The range of SSN is similarly limited for the QN observations in Tables 5 and 6 . In addition, there are insufficient observations at $4.64 \mathrm{MHz}$ on the QN path and therefore this frequency has been omitted.

[23] The Doppler spread on the subauroral paths (NB and UB) does not change with sunspot number during the day at the lower frequencies (4.64 to $8.01 \mathrm{MHz}$ ), while there is a small sudden increase between $\mathrm{SSN}=65$ and $\mathrm{SSN}=105$ at the higher frequencies. The absence of data at SSN between these values means that it is not possible to determine how the spread changes in this range (e.g., whether there is a gradual change from one state to the other or a sudden change) - this limitation of the current data set applies to all of the following discussion. At night, the step in Doppler spread is larger (e.g., at $11.12 \mathrm{MHz}$ winter night, the Doppler spread is $1.7 \mathrm{~Hz}$ for $\mathrm{SSN} \leq 65$ and $11.1 \mathrm{~Hz}$ for $\mathrm{SSN} \geq 105$ ) and is observed on all frequencies except 4.64 MHz and $8.01 \mathrm{MHz}$ (although note that there are no observations at $\mathrm{SSN}>65$ for $8.01 \mathrm{MHz}$ ). The composite multipath spread tends to increase linearly with SSN, although there are a few examples (e.g., $11.12 \mathrm{MHz}$, winter night) where there is a sudden increase at high SSN. The behavior of the spreads is consistent with the signal scattering from irregularities in the poleward wall of the trough or in the auroral oval previously discussed [Warrington and Stocker, 2003; Stocker and Warrington, 2011; Siddle et al., 2004a, 2004b; Stocker et al., 2009]. Such scattering will lead to higher Doppler spread since the irregularities will be moving at different velocities, and generally higher multipath spread since the time-of-flight of such off-great circle propagation modes is much longer than that of the on-great-circle modes that might also be present [e.g., see Siddle et al., 2004a, 2004b]. At solar minimum, propagation via the auroral oval or poleward wall of the trough was significantly less common than at solar maximum [Warrington et al., 2007] and hence the Doppler and delay spreads are also lower at lower levels of solar activity.

[24] On the polar cap path (QN), at frequencies up to $10.39 \mathrm{MHz}$, the Doppler spread tends to increase with $\mathrm{SSN}$, either linearly or with a sudden increase at relatively low SSN (e.g., for $6.95 \mathrm{MHz}$ winter night, the Doppler spread is $3.5 \mathrm{~Hz}$ at $\mathrm{SSN}=5$ and $6.3 \mathrm{~Hz}$ at $\mathrm{SSN} \geq 25$ ). The behavior is very different at $11.12 \mathrm{MHz}$, where the Doppler spread either peaks at $\mathrm{SSN}=35$ or more usually decreases with increasing SSN. The trends are unclear at 14.36 $\mathrm{MHz}$, except in one case (Equinox night) where it increases with increasing SSN. It is also noteworthy that the Doppler spreads are generally higher than those observed on the subauroral paths except when the latter are affected by scatter, e.g., during winter night. Although at a much higher radio frequency, it is interesting to note that polar patches are a significant cause of VHF/UHF scintillations and patch

Table 5. Behavior of 95th Percentile of Doppler Spread With Smoothed Sunspot Number for Qaanaaq to Ny-Ålesund ${ }^{\mathrm{a}}$

\begin{tabular}{|c|c|c|c|c|c|}
\hline Frequency $(\mathrm{MHz})$ & 6.95 & 8.01 & 10.39 & 11.12 & 14.36 \\
\hline \multicolumn{6}{|c|}{ Winter } \\
\hline Day & L:0.044+4.3 & L:0.023+4.5 & ND & $\mathrm{L}:-0.039+5.5$ & ND \\
\hline \multicolumn{6}{|c|}{$\begin{array}{r}\text { S1:5-25, 3.0-6.5 } \\
\text { Equinox }\end{array}$} \\
\hline Day & $L: 0.041+3.2$ & $\mathrm{~L}: 0.030+3.6$ & SI:5-15, 3.5-5.0 & $P: 35,5.0$ & ND \\
\hline \multicolumn{6}{|c|}{ Summer } \\
\hline Day & ND & ND & $\mathrm{L}: 0.034+2.5$ & $\mathrm{~L}:-0.026+3.3$ & ND \\
\hline Night & ND & $\mathrm{L}: 0.022+1.7$ & SI:55-65, 2.3-4.5 & $\mathrm{L}:-0.041+3.5$ & ND \\
\hline
\end{tabular}

${ }^{\mathrm{a}} \mathrm{ND}$, insufficient data or otherwise unable to determine trend; L, linear trend with gradient + constant given; SI, sudden increase between SSN values of $X-Y$ with mean spread levels (in Hz) before and after of A-B; P, Peak located at a sunspot number of $X$ with a spread of $Y$ (in $\mathrm{Hz}$ ). 
Table 6. Behavior of 95th Percentile of Composite Multipath Spread With Smoothed Sunspot Number for Qanaaq-Ny-Ålesund ${ }^{\mathrm{a}}$

\begin{tabular}{|c|c|c|c|c|c|}
\hline Frequency (MHz) & 6.95 & 8.01 & 10.39 & 11.12 & 14.36 \\
\hline \multicolumn{6}{|c|}{ Winter } \\
\hline Day & $\mathrm{L}: 0.015+0.4$ & $\mathrm{~L}: 0.005+0.3$ & ND & Fix $=0.2$ & ND \\
\hline Night & $\mathrm{L}: 0.007+0.1$ & ND & ND & ND & ND \\
\hline \multicolumn{6}{|c|}{ Equinox } \\
\hline Day & ND & $\mathrm{L}: 0.005+0.3$ & Fix $=0.3$ & Fix $=0.2$ & $\mathrm{~L}: 0.003+0.2$ \\
\hline Night & ND & $\mathrm{L}: 0.003+0.3$ & $\mathrm{~L}: 0.004+0.1$ & Fix $=0.2$ & Fix $=0.2$ \\
\hline \multicolumn{6}{|c|}{ Summer } \\
\hline Day & ND & ND & Fix $=0.2$ & Fix $=0.2$ & ND \\
\hline Night & ND & $\mathrm{L}: 0.005+0.3$ & Fix $=0.2$ & Fix $=0.1$ & ND \\
\hline
\end{tabular}

${ }^{\mathrm{a}} \mathrm{ND}$, insufficient data or otherwise unable to determine trend; Fix $=X \mathrm{~Hz}$. Spread is constant or varies only by measurement precision $(0.1 \mathrm{~ms})-$ lower value is given; $\mathrm{L}$, linear trend with gradient + constant given.

activity, and hence scintillation increases, with SSN and during the winter [Dandekar, 2002; Basu et al., 1988]. In general, an increase in Doppler spread is apparent with increasing SSN. However, this is inconsistent with the decrease in Doppler spread with SSN for $11.12 \mathrm{MHz}$. For example, for $\mathrm{SSN}=60-70$, the median and 95th percentile values of the Doppler spread are 1.0 and $1.5 \mathrm{~Hz}$ for $11.12 \mathrm{MHz}$, while they are $1.5 \mathrm{~Hz}$ and $5.5 \mathrm{~Hz}$ for $10.39 \mathrm{MHz}$. On days where high spreads are seen at $10.39 \mathrm{MHz}$, the propagation modes at the two frequencies appear to be the same (so propagation via a $1 \mathrm{E}$ mode is not leading to a reduced spread at $11.12 \mathrm{MHz}$ ). However, the signal strength at $11.12 \mathrm{MHz}$ is generally lower than that observed at $10.39 \mathrm{MHz}$, so it is possible that when the signal is highly Doppler spread the level of the individual signal components is reduced to below the noise floor and hence the spread signals are not detected. The composite multipath spread for the lower frequencies increases with SSN, while for the higher frequencies is generally constant. For the lower frequencies, the increase in SSN will tend to increase the number of propagation modes available and hence the multipath spread, but for the higher frequencies, propagation is generally via a single hop irrespective of SSN.

\section{Concluding Remarks}

[25] In addition to signal-to-noise and interference ratios, the supportable data rate on HF radio communication links in a large part depends on channel characteristics such as the delay and Doppler spreads. Digital Radio Mondiale (DRM), for example, when operated at $21 \mathrm{kbit} / \mathrm{s}$ can tolerate a delay spread of $5 \mathrm{~ms}$ and a Doppler spread of $3 \mathrm{~Hz}$ provided that the SNR exceeds $21 \mathrm{~dB}$. Reducing the data rate to $7.6 \mathrm{kbit} / \mathrm{s}$ increases the delay and Doppler spread tolerances to $7 \mathrm{~ms}$ and $6 \mathrm{~Hz}$, respectively, provided that the SNR exceeds 17 dB [Smith and Angling, 2003]. The performance of other modem types (e.g., those that conform to the STANAG 4285 or MIL-STD-188-110B standards) is similarly constrainedan indication of the limiting values for a range of these waveforms available within a particular make/model of modem is given in Table 7 (information from Brown [2001]). STANAG 4415 is a 75 bps modem standard designed to tolerate, as a minimum required performance, large delay and Doppler spreads of up to $10 \mathrm{~ms}$ and $50 \mathrm{~Hz}$, respectively at SNR values of $0 \mathrm{~dB}$.

[26] This paper presents results from an extensive set of measurements undertaken over northerly paths: two subauroral

Table 7. Approximate Levels of Multipath and Doppler Spreads That Can Be Tolerated for a Range of Waveforms Available Within a Particular Make/Model of Modem [Brown, 2001]

\begin{tabular}{|c|c|c|c|c|}
\hline Modem Waveform & Interleaver Length & Data Rate (bps) & Multipath Tolerance (ms) & Doppler Tolerance $(\mathrm{Hz})$ \\
\hline FSK & & 75 & 5.0 & 40.0 \\
\hline FSK & & 300 & 3.0 & 14.0 \\
\hline FSK & & 600 & 1.0 & 2.0 \\
\hline STANAG 4285 & $\mathrm{~L}$ & 75 & 6.0 & 32.0 \\
\hline STANAG 4285 & $\mathrm{~S}$ & 75 & 6.0 & 28.0 \\
\hline STANAG 4285 & $\mathrm{~L}$ & 300 & 5.0 & 20.0 \\
\hline STANAG 4285 & $\mathrm{~S}$ & 300 & 5.0 & 18.0 \\
\hline STANAG 4285 & $\mathrm{~L}$ & 1200 & 5.0 & 10.0 \\
\hline STANAG 4285 & $\mathrm{~S}$ & 1200 & 5.0 & 8.0 \\
\hline STANAG 4285 & $\mathrm{~L}$ & 2400 & 5.0 & 4.0 \\
\hline STANAG 4285 & $\mathrm{~S}$ & 2400 & 5.0 & 4.0 \\
\hline MIL-STD-188-110B & VL & 3200 & 5.0 & 3.5 \\
\hline MIL-STD-188-110B & VS & 3200 & 5.0 & 2.5 \\
\hline MIL-STD-188-110B & VL & 4800 & 4.0 & 3.0 \\
\hline MIL-STD-188-110B & VS & 4800 & 4.0 & 2.0 \\
\hline MIL-STD-188-110B & VL & 6400 & 4.0 & 2.5 \\
\hline MIL-STD-188-110B & VS & 6400 & 4.0 & 1.5 \\
\hline MIL-STD-188-110B & VL & 8000 & 4.0 & 2.0 \\
\hline MIL-STD-188-110B & VS & 8000 & 4.0 & 1.0 \\
\hline MIL-STD-188-110B & VL & 9600 & 4.0 & 2.0 \\
\hline MIL-STD-188-110B & VS & 9600 & 3.5 & 0.5 \\
\hline
\end{tabular}

${ }^{\mathrm{a}}$ The interleaver length refers to options available within the standard: very short (VS), short (S), long (L), and very long (VL). 
paths aligned along the midlatitude trough (UB and NB) and one path $(\mathrm{QN})$ contained entirely within the polar cap. The Doppler spreads on the polar cap path are significantly larger than those on the subauroral path except for winter or equinoctial nights during periods of high-solar activity, while the delay spread tends to be smaller. For both polar cap and subauroral paths, the Doppler spread is larger in winter. For UB and NB, the daytime Doppler spread does not change with SSN, but at night it is much higher at high SSN (particularly during the winter and equinoxes) as a result of scatter from the auroral oval or poleward wall of the trough. The delay spread tends to increase linearly with SSN for the subauroral paths. For the polar cap path, the data set covers a narrower range of sunspot values, but at lower frequencies an increase in the Doppler spread with increasing SSN can be identified (at the higher frequencies, $\geq 11.12 \mathrm{MHz}$, the trends are less clear). The delay spread increases with SSN at the lower frequencies, whereas at the higher frequencies, the observations indicate that the propagation tends to be single moded and therefore the delay spread does not change with SSN. As the delay and Doppler spread values are limiting parameters for the successful operation of particular modem types, an understanding of how these parameters vary with position, frequency, time of day, season, and sunspot number is crucial in planning and operating HF radio systems. The northerly ionosphere is a particularly challenging region in this regard as delay and Doppler spreads can significantly exceed those for similar length paths at midlatitudes.

[27] Acknowledgments. The authors are grateful to ARCFAC for supporting the measurements at Ny-Ålesund, to Svend Erik Ascanius of the Qaanaaq Geophysical Observatory for hosting an HF transmitter, and the Nurmijärvi Geophysical Observatory for hosting the other transmitter. The authors also gratefully acknowledge EPSRC for supporting some of this research under grants GR/N16877/01, GR/N66056/01, and EP/C014642/1.

\section{References}

Angling, M. J., P. S. Cannon, N. C. Davies, T. J. Willink, V. Jodalen, and B. Lundborg (1998), Measurements of Doppler and multipath spread on oblique high latitude HF paths and their use in characterising data modem performance, Radio Sci., 33(1), 97-107, doi:10.1029/97RS02206.

Arthur, P. C., and M. J. Maundrell (1997), Multidimensional HF modem performance characteristics, paper presented at the IEE Seventh International Conference on HF Radio Systems and Techniques.

Basu, S., E. MacKenzie, and S. Basu (1988), Ionospheric constraints on VHF/UHF communications links during solar maximum and minimum periods, Radio Sci., 23(3), 363-378, doi:10.1029/RS023i003p00363.

Brown, D. J. (2001), Link maintenance and channel evaluation techniques for $\mathrm{HF}$ radiocommunication links, $\mathrm{PhD}$ thesis, University of Leicester.

Buchau, J., B. W. Reinisch, E. J. Weber, and J. G. Moore (1983), Structure and dynamics of the winter polar cap F region, Radio Sci., 18(6), 995-1010, doi:10.1029/RS018i006p00995.

Dandekar, B. S. (2002), Solar cycle dependence of polar cap patch activity, Radio Sci., 37(1), 1013, doi:10.1029/2000RS002562.
MacDougall, J., and P. T. Jayachandran (2007), Polar patches: Auroral zone precipitation effects, J. Geophys. Res., 112, A05312, doi:10.1029/ 2006JA011930.

Rodger, A. S., R. J. Moffett, and S. Quegan (1992), The role of ion drift in the formation of ionization troughs in the mid- and high-latitude ionosphere - A review, J. Atmos. Sol. Terr. Phys., 54(1), 1-30, doi:10.1016/ 0021-9169(92)90082-V.

Siddle, D. R., A. J. Stocker, and E. M. Warrington (2004a), The time-offlight and direction of arrival of HF radio signals received over a path along the mid-latitude trough: Observations, Radio Sci., 39, RS4008, doi:10.1029/2004RS003049.

Siddle, D. R., N. Y. Zaalov, A. J. Stocker, and E. M. Warrington (2004b), The time-of-flight and direction of arrival of HF radio signals received over a path along the mid-latitude trough: Theoretical considerations, Radio Sci., 39, RS4009, doi:10.1029/2004RS003052.

Siddle, D. R., A. J. Stocker, E. M. Warrington, N. Y. Zaalov, and M. J. Homam (2013), Simultaneous observations of trans-ionospheric and HF propagation within the polar cap, Radio Sci., 48, doi:10.1002/ rds. 20062.

Smith, O. J., and M. J. Angling (2003), Optimising quality of service of a new digital radio broadcasting system Ninth International Conference on HF Radio Systems and Techniques, IEE Conf. Publ., 493, 96-101.

Stocker, A. J., and E. M. Warrington (2011), The effect of solar activity on the Doppler and multipath spread of HF signals received over paths oriented along the mid-latitude trough, Radio Sci., 46, RS1014, doi:10.1029/2010RS004482.

Stocker, A. J., E. M. Warrington, and D. R. Siddle (2007), A comparison between measured and predicted parameters of HF signals propagating along the mid-latitude trough and within the polar cap, Radio Sci., 42, RS3019, doi:10.1029/2006RS003557.

Stocker, A. J., N. Y. Zaalov, E. M. Warrington, and D. R. Siddle (2009), Observations of HF propagation on a path aligned along the mid-latitude trough, Adv. Space Res., 44(6), 677-684, doi:10.1016/j.asr.2008.09.038.

Tulunay, Y., and J. Sayers (1971), Characteristics of mid-latitude trough as determined by electron density experiment on Ariel III, J. Atmos. Sol. Terr. Phys., 33(11), 1737-1761, doi:10.1016/0021-9169(71)90221-2.

Warrington, E. M. (1998), Observations of the directional characteristics of ionospherically propagated HF radio channel sounding signals over two high latitude paths, IEE Proc. Microwaves, Antennas Propag., 145(5), 379-385, doi:10.1049/ip-map:19982068.

Warrington, E. M., and A. J. Stocker (2003), Measurements of the Doppler and multipath spread of HF signals received over a path oriented along the mid-latitude trough, Radio Sci., 38(5), 1080, doi:10.1029/2002RS002815.

Warrington, E. M., N. C. Rogers, and T. B. Jones (1997), Large HF bearing errors for propagation paths contained within the polar cap, IEE Proc. Microwaves, Antennas Propag., 144(4), 241-249, doi:10.1049/ipmap: 19971187.

Warrington, E. M., A. J. Stocker, N. Y. Zaalov, and D. R. Siddle (2007), Observations of HF propagation on a path aligned along the mid-latitude trough, Nordic HF-07, page 1.3.1-1.3.10.

Zaalov, N. Y., E. M. Warrington, and A. J. Stocker (2003), The simulation of off-great circle HF propagation effects due to the presence of patches and arcs of enhanced electron density within the polar cap ionosphere, Radio Sci., 38(3), 1052, doi:10.1029/2002RS002798.

Zaalov, N. Y., E. M. Warrington, and A. J. Stocker (2005), A ray-tracing model to account for off-great circle HF propagation over northerly paths, Radio Sci., 40, RS4006, doi:10.1029/2004RS003183.

Zaalov, N. Y., E. M. Warrington, and A. J. Stocker (2007), The effect of geomagnetic activity on the channel scattering functions of HF signals propagating in the region of the mid-latitude trough and auroral zone, Radio Sci., 42, RS4005, doi:10.1029/2006RS003611.

Zaalov, N. Y., H. Rothkaehl, A. J. Stocker, and E. M. Warrington (2013), Comparison between HF propagation and DEMETER satellite measurements within the mid-latitude trough, J. Adv. Space Res., doi:10.1016/j. asr.2013.05.023. 